\title{
Disclosure of Parental HIV Positive Status: What, Why, When, and How Parents Tell Their Children in the Era of HAART in South Africa
}

\author{
Sphiwe Madiba, Chidi Matlala \\ School of Public Health, University of Limpopo, Medunsa Campus, Pretoria, South Africa. \\ Email: Sphiwe_madiba@embenet.com
}

Received June $15^{\text {th }}$, 2012; revised July $16^{\text {th }}$, 2012; accepted July 27 ${ }^{\text {th }}, 2012$

\begin{abstract}
The aim of the study was to explore the decision to and the process of disclosure of parental HIV status to children. Focus group interviews were conducted with 21 parents of 39 children aged 7 - 18 years. Participants were recruited from a highly active antiretroviral treatment (HAART) program of an academic hospital in South Africa. Parents disclosed more to older children than to younger children in the same family, and the breadth and depth of the information shared was depended on the age of the child. Communication with adolescent children included topics on HIV prevention and unsafe sexual practices. For parents with a long history of sickness, disclosure occurred soon after the diagnosis was made, when they had not commenced with antiretroviral treatment (ART). They disclosed to prepare their children for HIV related emergencies and imminent death. Parents also expected support from their older children after disclosure. Some parents were forced to disclose because children suspected their HIV status, and parents could not continue to hide symptoms like severe weight loss. In addition, parents disclosed to educate children on how to protect themselves from HIV infection. For most parents, disclosure was unplanned, emotive, and burdened with anxiety and fear of rejecttion by their children. However, when the decision to disclose was made, parents were honest and open and informed their children that they were HIV positive. Parents may benefit from disclosure support services, and health care providers can assist parents in deciding when and how to disclose.
\end{abstract}

Keywords: South Africa; Disclosure; HIV; Children; Parents; Antiretroviral Treatment

\section{Introduction}

South Africa is home to the world's largest population of people living with HIV (PLWH), and the total number of PLWH in South Africa in 2009 was 5.7 million [1]. In response to the HIV epidemic, the government of South Africa developed a strategy to provide antiretroviral treatment (ART) to people who need it, consequently an increased number of people have access to ART in South Africa [2]. Similar to well developed countries, the increasing availability of ART in South Africa have led to a change in the conceptualization of HIV from a fatal disease to a chronic illness [2,3]. Whereas in the absence of ART HIV was considered to be fatal, in the context of ART it is no longer associated with impending death [4-6]. ART increases the length and quality of life of HIV-infected people by reversing the immunodeficiency characteristic of AIDS [7]. As HIV becomes more of a chronic disease HIV positive parents are more likely to raise their children for many years, and disclosure of parental HIV status to children has become an increasingly significant issue [8].

Disclosure of parental HIV status to children has been shown to affect the well-being of children, parents, and family positively [9]. Disclosure of the mother's HIV status to children is associated with better adherence to clinic appointments, as mothers do not need to hide their medical care [8]. However, the process of disclosing HIV to children is one of the most difficult issues parents deal with, most parents, particularly mothers, struggle with decisions about when and how to disclose HIV to their children [10-14]. In addition, parents face the difficult decision of what detail information to share about their HIV status with their children [15]. The problems mothers anticipate in disclosing, translate into low rates of disclosure to children in both developed and developing countries $[9,16]$.

Earlier studies show that disclosure is related to parental desire to prepare children to face parental death [17]. However, with increased access to ART, HIV has become a chronic illness, and an HIV diagnosis does not necessarily signal imminent death, and may not influence the 
decision for disclosure to children [13,16]. According to Schrimshaw and Siegel [13], PLWH live healthier lives because of the increased access to ART; therefore their rates and reasons for disclosure to children may differ from the pre ART era.

The increased access to ART and increased survival of adults and children in South Africa calls for an in-depth understanding of the decision to and the process of parental HIV disclosure to their children. Available data show that most studies examining parental disclosure to children before and after the introduction of ART were conducted in developed countries; only a few of these studies are from developing countries $[9,18]$. A recent systemic review on parental disclosure practices [9] shows that only eight (20\%) of the reviewed articles were from African and Asian countries. Qiao et al. [9] further argues that disclosure practices of families affected by HIV living in developing countries are likely to differ because of various cultural and social contexts. Furthermore, most of the qualitative studies conducted in developing countries focused on parental disclosure from the perspective of the mothers only. This study used a qualitative approach to explore the process of parental HIV disclosure to children from the perspectives of fathers and mothers in the era of highly active antiretroviral therapy (HAART). The aim of the study was to explore with a sample of parents enrolled in an HAART program of an academic hospital in South Africa about when, what, why, and how they disclose their HIV status to their children.

\section{Methods and Materials}

\subsection{Study Design}

We conducted focus group (FG) interviews with participants recruited from an adult HIV clinic of an academic hospital in South Africa. Recruitment of study participants started after ethical approval by the Medunsa Ethics and Research Committee. Data were collected between November 2010 and January 2011, and at the time of data collection, more than 1000 adult patients were receiving ART from this clinic.

\subsection{Data Collection}

The authors and a research assistant conducted the FG interviews, and all are trained in methods of qualitative focus group design. Two open ended FG guides, one for disclosed and one for non-disclosed parents was used for the FG interviews. The guides were developed in English and translated into Setswana, a local language spoken by most participants in the study site. Participants were recruited during their routine visit to the clinic; recruitment was done in the mornings while they awaited their turn to be seen by the doctor, and or collect medication. After information was provided about the study, participants who were interested in being a part of the study and met the inclusion criteria of being a biological parent of a child aged between 7 and 18 years were selected for the FG interviews. We obtained a written informed consent from individual participants prior to the start of the interview. The FG interviews were conducted in Setswana and were audio recorded with the participants' permission. FG interviews lasted for about 60 to 90 minutes. All FG interviews were conducted on the same day of recruitment while participants waited for their medication. Participants were served refreshments at the end of the interviews. A total of six FG interviews were conducted with disclosed and non-disclosed parents of children aged between 7 - 18 years. Each FG interview had an average of seven participants with a total of 44 participants.

Socio-demographic information of the participants and their children was collected at the end of the FG interviews using a brief self-administered tool. The questionnaire collected demographic information including age, level of education, marital status, employment status, date of HIV diagnosis, and period on ART. Participants provided information on their children including number of children, the age of the children, gender, the HIV status of the children, and whether or not they had disclosed their HIV status to their children.

The Medunsa Research Ethics Committee of the University of Limpopo granted ethical approval for the study. Permission to conduct the study was obtained from the hospital management of Dr George Mukhari Academic hospital. Participation in the study was voluntary, and the researchers ensured confidentiality throughout data collection. Informed consent was obtained from participants prior to the FG interviews.

\subsection{Data Analysis}

The recorded FG interviews were first transcribed verbatim in Setswana by a transcriptionist and then translated into English by the authors. Each transcribed transcript was reviewed for accuracy by replaying each interview tape whilst reading and translating the transcript. The primary coding of the transcripts was undertaken by the authors. Multiple readings of one transcript were undertaken by the authors who independently identified major themes from the transcript. From the initial reading, a set of major themes related to the process of disclosure between HIV positive parents and their children were identified and defined. NVivo version 8 was used in the application of themes to the remaining transcripts to determine if new themes identified from additional readings are consistent with themes identified from the initial reading of the transcript. Themes that were consistent in terms of the process of disclosure became categories. 


\section{Results}

\subsection{Sample Description}

This paper presents data from three FG interviews conducted with a sample of disclosed HIV positive parents who had children aged between 7 - 18 years. A total of 21 parents aged between 20 - 50 years participated in the FG interviews. Table 1 shows the demographic profile of

Table 1. Socio-demographic profile of participants.

\begin{tabular}{|c|c|c|}
\hline Variable name & Frequency & Percent \\
\hline \multicolumn{3}{|l|}{ Age } \\
\hline $20-30$ & 1 & 4.8 \\
\hline $30-40$ & 11 & 52.4 \\
\hline $40-50$ & 7 & 33.3 \\
\hline $50-60$ & 2 & 9.5 \\
\hline \multicolumn{3}{|l|}{ Gender } \\
\hline Male & 5 & 23.8 \\
\hline Female & 16 & 76.2 \\
\hline \multicolumn{3}{|l|}{ Employment status } \\
\hline Unemployed & 12 & 57.1 \\
\hline Employed & 4 & 19.1 \\
\hline $\begin{array}{cc}\text { Part } & \text { time } \\
\text { employment } & \\
\end{array}$ & 5 & 23.8 \\
\hline \multicolumn{3}{|l|}{ Level of education } \\
\hline Primary education & 10 & 47.6 \\
\hline Secondary education & 6 & 28.6 \\
\hline Grade 12 & 4 & 19.1 \\
\hline Tertiary education & 1 & 4.8 \\
\hline \multicolumn{3}{|l|}{ Marital status } \\
\hline Single & 13 & 61.9 \\
\hline Married & 5 & 23.8 \\
\hline Living with partners & 1 & 4.8 \\
\hline Widowed & 2 & 9.5 \\
\hline \multicolumn{3}{|l|}{ No. of children } \\
\hline One child & 7 & 33.3 \\
\hline Two children & 10 & 47.6 \\
\hline Three children & 4 & 19.1 \\
\hline \multicolumn{3}{|l|}{$\begin{array}{l}\text { No. of children parents } \\
\text { disclosed to }\end{array}$} \\
\hline One child & 11 & 52.38 \\
\hline Two children & 8 & 38.1 \\
\hline Three children & 2 & 9.52 \\
\hline
\end{tabular}

the participants. The 21 parents cared for 39 children aged between 7 and 18 years. Sixteen of the parents disclosed to all of their children while five told some, but not all of their children. A total of 33 out of 39 children were told about the HIV status of their parent. Only one of the disclosed children was HIV positive.

\subsection{Themes}

Four major themes emerged through analysis Table 2: what parents tell, when parents tell, why parents tell, and how parents tell children during disclosure of parental HIV status. Each of these themes is described below.

\subsubsection{What Parents Tell}

The data show that when the decision to disclose was taken, most parents were honest in disclosing HIV to their children and full disclosure occurred. Parents told their children that they were HIV positive, and also gave additional information about their medication:

I sat down and talked to them, and told them that I went to the clinic and learned that I am HIV positive..., you need to know that I am HIV positive. They did not say anything; they came to me and gave me hugs (Single mother of 2 children).

I sat them down because they are old enough the older one was 17 years, and the younger one was 13 years, and I said..., you see this medication that I am taking protects me from the disease called HIV, so I am HIV positive. How I got it, when and where I cannot tell, I do not know and I won't know (Single mother of 2).

Some parents requested their children to keep the disclosure secret and not discuss it with other people. The data show that even when parents did not give their children instructions not to tell other people, they believed that their children understood the nature of the disease and knew that they should not tell people outside the family. Secrecy is used to protect children from social rejection and discrimination that may be subjected to the whole family or to the children:

I started telling the child that she must not tell anybody, because people are going to diagnose me. After giving birth to my baby, some woman in the neighbourhood asked my daughter whether her sibling is being breast fed. She said "she is drinking from the bottle" and the woman wanted to know whether the

Table 2. Summary of identified themes.

What parents tell
When do parents tell?
Why parents tell
How parents tell


name of the milk formula was Nan because HIV positive people give their babies this milk. I said, "don't tell her, do not tell anybody" even though they will hear about it..., they will hear somewhere else; you must never talk about that with people (Single mother of 2 children).

At seventeen, she knows that it is a family secret and then if you tell she will never talk (Single mother of 3 children).

\subsubsection{When Do Parents Tell?}

Participants were asked about the time it took from diagnosis to the time they disclosed their HIV diagnosis to their children. Our data show that for some of the parents, disclosure was easy, and they disclosed soon after the diagnosis was made.

I did not take long, immediately I found out that I was HIV positive I told them, I told them when I was still in counselling, I told them that I am positive when I was going through counselling (Single mother of 2 children).

I just told them straight from the beginning that I'm sick and told them that they must keep on taking care of themselves and that they must not be surprised when I keep on taking medication, some of the pills are for TB and the others are for AIDS (Divorced father of 2 children).

In contrast, some parents disclosed long after the HIV diagnosis. These parents found it emotional and difficult to discuss their HIV status with their children.

I took a long time without telling him, I waited until after he completed grade 12. I was scared that he will feel miserable and maybe think my mother is dying, my father is dead, my mother is also going to die..., so who are we going to be left with..., what is going to happen? So I was scared to hurt him, and I did not tell him anything until he completed grade 12. After completing grade 12, I told him (Widowed mother of 2 children).

It was scary, but I thought that I must just tell them. I used to think that someone with HIV dies immediately not knowing that one can survive while taking treatment (Married father of 2 children).

Some parents believe that disclosure to children should occur before their health deteriorates as children can be more easily reassured that the parent is not going to die in the near future.

It will not be right to tell them that you are sick when you are bedridden, because you can die at any time. So, when you tell them while you are still fine they will heal and accept that their mother is HIV positive. I mean I don't have to hide that I am HIV positive, I must tell her that I'm HIV and that one day I will be in the stage where I will have AIDS and will leave you, and you will be alone (Single mother of 2 children).

One mother, who was critically ill when she was diagnosed, delayed disclosure while she continued taking $A R T$ waiting for her health status to improve. She then used her previous ill health and improved health status to reassure her children who thought that their parent was going to die soon, as this mother explains.

The older one cried. She thought that I was going to die; I was going to get ill and die. I said do you remember the time when I was seriously ill and had TB, it was TB and this disease. She wanted to know if it can be cured and I said the medication that I take suppress the disease but does not cure it, I will take them for the rest of my life. She does not worry anymore because she can see that I am healthy, and I do not get sick anymore (Single mother of 1 child).

\subsubsection{Why Parents Tell}

For parents who were critically ill at the time of disclosure, they disclosed because they wanted their children to take care of them in case their health suddenly deteriorates. In the same breath, parents wanted to prepare their children for future AIDS-related illness so that they would know what to do in an emergency should the health of the parent suddenly deteriorates. This is in contrast to parents who believed that disclosure should occur when the parent's health has improved. For these parents, disclosure was motivated by the need for support from their children:

I decided to tell them because life is difficult, I can become ill at any time, and the children won't know what is happening with me. So if I told them about my condition, they can rush me to the doctor or call an ambulance to come and take me so that I can get help immediately (Single mother of 2 children).

There is nothing I can do on my own because I'm relying on them, if I can be critically ill they must know what I suffer from and also to know what I need (Married father of 2 children).

If I collapse my child will know what to do, the first thing she will call the ambulance, and secondly she will show the ambulance people my treatment (Single mother of 1 child).

Parents also disclosed because they wanted to educate their children about the disease so that they can take care of themselves and prevent getting infected from HIV. The need to educate children on how to avoid HIV infection was motivated by the fact that parents disclosed to older or adolescent children in the family.

What made me tell my child is that I did not want her to engage in things that she is not supposed to be engaged in. I was not talking to her as a parent; I was talking to her as if I am counselling her. So that she can see that this disease exists, so that she must not think that only other people can be infected, or only older people 
they must know that they are still growing up and that this thing exists and that she must take care of herself and behave well (Single mother of 2 children).

I decided to tell them that I'm HIV positive so that they must always take care of themselves. They must not fall into the same trap I fell into. If you don't tell you will be unfair to your children. Because we could not protect ourselves from being infected, and now this illness is everywhere, they must not go through the same mistakes as we did (Divorced father of 2 children).

Parents, particularly mothers, used disclosure as an opportunity to educate their children about how to avoid contact with blood in case of an emergency at home:

Because you are going to need help from the family..., so the children must know that when you bleed they must wear gloves or something that they can use to help you so that they must not end-up being infected (Single mother of 2 children).

The reason I told my children that I had this disease I wanted to protect them, maybe if I have an accident and I am bleeding I want them to know how to help me (Single mother of 3 children).

The data also show that some of the parents who had a long history of illness were forced to disclose to their children. Children could identify some of the signs and symptoms related to HIV illness and started to suspect their parent's HIV status. Parents relate how their children confronted them about their illness.

I use to be fat, so when I lost weight they asked me why I was losing weight so much. They wanted to know why I have flu every two weeks; they asked why my flu was not getting cured. They said, "at school they teach us that if a person has persistent flu and is not cured it might be that they are HIV positive" (Single mother of 3 children).

The way it was, they were already suspecting something. These children were already suspecting even the family because I was seriously ill..., it was obvious even for the people I am staying with. I was seriously ill, emaciated, and critically ill, and I was unable to do anything (Married father of 3 children).

But I took long before telling her and it came to a time that she asked me about the treatment, she wanted to know what the pills are for and why I was drinking them at a specific time all the time. I told her that I am sick, and she told me that at school, they told them about HIV. She said you know these pills are like the ones that the nurse was teaching us about when she visited our school. I said no these are not like those. She then said, "let's go to the clinic so that you must be tested". I said why, she said mom I can see that you became thin, and you have changed. I said no my child I am not like that. She cried and said "I won't tell anyone if you can tell me, I will keep it a secret". I then sat her down and explained to her that I am positive and that I started taking my treatment (Single mother of 2 children).

Forced disclosure also occurred because children asked direct questions about their parent's treatment more especially the pattern of medication. This also suggests that the children were suspecting their parent's illness based on observing their peculiar pattern of medication.

Yes, but they saw more pills, and they asked, and I explained to them that some of this pills are for HIV and these other ones are for TB (Divorced father of 2 children).

I told her because she was questioning me when she saw me taking medication for two months she said when will you finish? I ended up telling her that these pills are for the rest of my life (Single mother of 3 children).

Parents also disclosed to prevent the possibility of children learning about the parent's HIV status from other people in the family or the community.

I think it is important to tell the child about your status as a parent. Because sometimes you don't tell the child and he/she hears it from other people. When the child hears it from other people it does not sound nice. The child might be angry with you and might leave home without telling you (Single mother of 3 children).

\subsubsection{How Parents Tell}

Data show that most participants first told their parents about their HIV status before disclosure to their children. In family-orientated societies family support is valued, and mothers especially may play a much more important role in the process of disclosure as expressed in the following statement:

It is your parents who must know your status first, after that, you disclose to your children and then to other relatives so that they can all give you support (Single mother of 3 children).

I think that my parent is the first to know and must know and has the right to know about my illness. I understand that she is the person who will feel more pain for me in everything that happens to me (Widowed mother of 2 children).

Disclosures often take place over the course of several conversations, though for most parents in this study it occurred in one sitting. For a few parents, disclosure was continuous, and they recounted times when they had talks about HIV related sexual and reproductive health topics with their children.

We talk, we sit down and talk, when we do not have anything to talk about, we talk about HIV (Single mother of 2 children).

When we are just sitting I explain to my child what is happening about AIDS. I tell her that she must not do it. I 
tell her that sex, I tell her that you are better because you have not started engaging into sex, so don't even start engaging yourself into sexual acts (Single mother of 1 child).

Parents in this study often disclosed to older children but not to younger children in the same family, and the majority of parents had more than 2 children. Mothers often delayed disclosure to the younger children because they questioned whether their younger children would understand the information given to them:

Well the younger one is 12 years he will be 13 years old I haven't told him anything (Widowed mother of 2 children).

My elder daughter knew for a long time it is her siblings that didn't know anything. She knew from 2008 that was positive because she was the elder one and she was matured. The other children started knowing this year when I became critically ill (Single mother of 3 children).

\section{Discussion}

The study describes the process of disclosing HIV between parents and their biological children and offers data on the information that parents share with their children, how this information is shared as well as the reasons parents disclose to their children. The findings show that the decision to disclose was difficult and emotional for all parents. Prior to disclosure, they were scared, anxious, and stressed that the child would react negatively to disclosure. Consequently, disclosure was first to their parents and sexual partners before parents disclosed to their children. Similar findings were reported $[14,19]$. Although disclosure to children is emotive for parents, most children who know their parents HIV status were informed by their parents. In this study and others, parents believed that they should be the ones to disclose their HIV status to their children [12]. The reason mothers take a leading role in disclosing to their children is because their decision to disclose is informed by the child's ability to understand the information. Mothers also want to disclose their illness to their children in a reassuring manner $[13,20]$. With regards to the time it took before parents disclosed to their children, we found that some parents disclosed soon after the diagnosis was made. For these parents, disclosure was motivated by self-benefit. They disclosed so that they could receive help and support from their children. Parents mentioned that they wanted their children to know their condition so that they could take care of them when their condition becomes critical. Similar findings where the decision to disclose is motivated by self-benefit were previously reported [12,18]. The authors suggest that disclosure makes it easier for parents to ask for, and receive support from their children and family once they knew the seriousness of the problem [12,18]. Earlier studies conducted with HIV positive mothers also report that one of the reasons they disclosed to their children was the need for support from older children [21]. Findings from this study and others show that children responded with gestures of comfort, acceptance and support to parental disclosure [20].

We further found that the health status of parents who disclosed soon after an HIV diagnosis was compromised, suggesting that the decision to disclose was also prompted by the parents' ill health. Evidence from previous studies shows that parents disclose to their children when their health deteriorate or when they believe that death is imminent [13-15,17,21,22]. These data further support the suggestion that self-interest plays a role in the parents' decision to disclose to their children. It should be noted that though self-interest plays a role in disclosure of HIV to children in this study, studies conducted prior to the availability of ART report that parents disclosed to prepare children to face parental death [17]. This phenomenon was also observed in this study. Although the participants were enrolled in an HAART program, most were diagnosed following a long history of illness, and disclosure occurred at a time when they suffered from a myriad of HIV opportunistic infections and had not commenced with their ART. Suggesting that disclosure occurred before they experienced the benefits of ART when they believed that death is imminent, hence the need for support from their children.

Disclosure also occurs within a context where children suspect their parents' HIV status. Children learn about HIV from various sources including the TV and at school and are able to identify some of the HIV related symptoms by observing their parents' deteriorating health condition $[18,23]$. One mother had been sick for a long time when her 11 year old advised her to go for an HIV test because she recognized some of the HIV related symptoms the mother had. We found that when children questioned parents about their deteriorating health, parents were forced to disclose. Forced disclosure to children was reported in other studies conducted with HIV positive mothers [14,15,18,19,21,23,24]. According to Armistead et al., [19] forced disclosure occurs when it becomes more difficult for mothers to hide their symptoms from their children. In this study, one of the symptoms that parents could not hide is severe weight loss. These are parents who were diagnosed after a long history of chronic HIV related illness. In contrast to parents who disclosed when their health condition was compromised, other parents believe that disclosure should be deferred when the parent is weak or critically ill.

Parents in this study and others felt that children should be prepared for future HIV related illness or death 
while the parent is healthy, so that children do not think that parental death is an immediate possibility. Parents believe that good physical state would help to reassure children that it was possible to live a relatively normal life for some time [13]. Before the availability of ART parents would disclose before their health begins to deteriorate [13], with increased access to ART, parents are likely to delay disclosure until their health become stable [14]. Similarly, parents in this study believed that if the child has seen the parent critically ill but become stable subsequent to taking ART, then the child may not be so fearful of HIV and will be better assured that the parent is not going to die soon. One mother in this study gave an account on how she made her child recall the time when she was critically ill, and compared that time to her current health status when she disclosed. Parents also used the medication as an introduction to the disclosure event and often told their children that the medication was protecting them from the disease.

One of the reasons parents in this study and other studied disclosed is to prepare children for emergency situations. Parents wanted children to know what to do in case of emergency, like when the parent suddenly falls seriously ill [13]. Consistent with other studies, parents in this study also used disclosure to educate their children about HIV, and on how to avoid contact with their parents' blood [10,13]. Similar to other studies, parents of older children and adolescents disclosed to educate them about HIV transmission and unsafe sexual practices $[13,21,25]$. Our study findings are in contrast with other studies in the region, a study conducted in Botswana, found that parents do not discuss sexual topics related to the transmission and prevention of HIV when they disclosed their HIV to children. The study argues that discussions around HIV transmission and sexual practices with children are taboo and inappropriate [15]. While in our study, one father believed that he had to be open and direct about HIV transmission to prevent his children from falling in the HIV trap that he finds himself. Furthermore, for some of the parents in this study, disclosure was a continuous process and often the conversations they had with their children were about HIV, safe sexual practices and prevention of HIV transmission.

In this study, parents disclosed to children for various reasons already discussed above. The reasons for disclosure determined the breadth and depth of the information parents share with their children. We found that when the decision to disclose was made, full disclosure occurred, and parents were open and honest and informed their children that they were HIV positive. For parents who disclosed to get support from children, disclosure focused on telling their children what to do in case their condition suddenly deteriorates from HIV related illness. While for parents who wanted to protect their children from being infected with HIV, the disclosure discussion focused on what to do to avoid contact with the blood of their parents in case of an accidental bleeding. In line with other studies, some parents told their children to keep the parent's HIV status secret $[12,14,18]$. It should be noted that parents who did not openly tell their children to keep the HIV status secret, expected their children not to tell because they are supposed to know that HIV is a family secret. The decision to keep the HIV status secret is founded on the desire to protect their children from ridicule, teasing, and social rejection, especially in an environment where stigma and discrimination are rife.

We further found that the age of the child was a key consideration in parental disclosure, and that it also determined how much information children got from their parents. This finding is in line with other studies $[10,12,14,16,19,20]$. Parents who had more than one child in this study, disclosed to older children earlier than to younger children. Older children were told about the parent's HIV status because parents believed that they were more matured to understand the disease, were more likely to offer support to the parent, know what to do in case of medical emergency, know how to avoid contact with parental blood and keep the disclosed diagnosis secret. These findings are consistent with previous studies $[14,17,26,27]$.

The study concludes that for most parents, disclosure to children was unplanned, emotive, and burdened with anxiety, and fear of rejection by their children. The anxiety and fear of disclosure should be viewed in the context where disclosure occurs in an environment characterized by stigma, discrimination, and fear of death from HIV/ AIDS. Consequently, parents disclosed more to older children than to younger children in the same family because older children were regarded as mature to keep the parents' HIV status secret. Disclosure was also characterized by honesty, openness, and full disclosure, where parents informed their children that they were HIV positive. However, the breadth and depth of the information shared is depended on the age of the child. Communication with adolescent children included topics on prevention of HIV transmission and unsafe sexual practices.

Despite enrolment in an HAART program, most parents disclosed to prepare their children for HIV related emergencies and imminent death of the parent. This was common amongst parents who disclosed when their health was severely compromised, and disclosed to receive support from their older children. Parents also disclosed to educate children to protect themselves from HIV infection. Lastly, parents were also forced to dis- 
close because children suspected their parents' HIV status, and they could not continue to hide symptoms like severe weight loss or deny their HIV status. This finding is critical in parental disclosure to children, and suggests that parents might not be able to control how their children learn about their HIV infection. When children suspect their parent's HIV infection, they live in fear of the pending death of their parents. Parents may benefit from disclosure support services to assist and guide the process of disclosure for both the parent and child. Health care providers have a role in assisting parents in deciding when and how to disclose. In counselling parents for disclosure, they should inform parents about the effects of disclosure and nondisclosure on their children.

\section{Acknowledgements}

The study was funded by the Directorate General for Development Cooperation (DGDC) through the Flemish Interuniversity council (VLIR-UOS). We thank Mr Nick Maubane, the research assistant, for his role in data collection. We also thank health care providers from the wellness clinic at the Dr George Mukhari Academic hospital for their guidance and assistance during data collection.

\section{REFERENCES}

[1] UNAIDS, "Report on the Global AIDS Epidemic,” UNAIDS, Geneva, 2009. http://www.unaids.org/en/dataanalysis/epidemiology/200 9aidsepidemicupdate/

[2] O. Shisana, T. Rehle, L. C. Simbayi, K. Zuma, S. Jooste, et al., "South African National HIV Prevalence, Incidence, Behaviour and Communication Survey 2008: A Turning Tide among Teenagers?” HSRC Press, Cape Town, 2009. http://www.hsrc.ac.za/Document-3239.phtml

[3] K. Bhaskaran, O. Hamouda, M. Sannes, F. Boufassa, A. M. Johnson, et al., "Changes in the Risk of Death after HIV Seroconversion Compared with Mortality in the General Population,” Journal of the American Medical Association, Vol. 300, No. 1, 2008, pp. 51-59. doi:10.1001/jama.300.1.51

[4] S. Biadgilign, A. Deribe, A. Amberbir and K. Deribe, "Barriers and Facilitators to Antiretroviral Medication Adherence among HIV-Infected Paediatric Patients in Ethiopia: A Qualitative Study,” AIDS Care, Vol. 6, No. 4, 2009, pp. 148-154.

[5] M. Ferris, K. Burau, A. M. Schweitzer, S. Mihale, N. Murray, et al., "The Influence of Disclosure of HIV Diagnosis on Time to Disease Progression in a Cohort of Romanian Children and Teens,” AIDS Care, Vol. 19, No. 9, 2007, pp. 1088-1094. doi:10.1080/09540120701367124

[6] S. Kallem, L. Renner, M. Ghebremichael and E. Paintsil, "Prevalence and Pattern of Disclosure of HIV Status in HIV-Infected Children in Ghana," AIDS and Behavior,
Vol. 15, No. 6, 2010, pp. 1-7.

[7] L. R. McKinnon, M. Kimani, C. Wachihi, N. J. Nagelkerke, F. K. Muriuki, et al., "Effect of Baseline HIV Disease Parameters on CD4+ T Cell Recovery after Antiretroviral Therapy Initiation in Kenyan Women," PLoS One, Vol. 5, No. 7, 2010, Article ID: e11434. doi:10.1371/journal.pone.0011434

[8] C. A. Mellins, E. Brackis-Cott, C. Dolezal, A. Richards, S. W. Nicholas, et al., "Patterns of HIV Status Disclosure to Perinatally HIV-Infected Children and Subsequent Mental Health Outcomes," Clinical Child Psychology and Psychiatry, Vol. 7, No. 1, 2002, pp. 101-114. doi:10.1177/1359104502007001008

[9] S. Qiao, X. Li and B. Stanton, "Disclosure of Parental HIV Infection to Children: A Systematic Review of Global Literature,” AIDS and Behavior, 2011, pp. 1-21.

[10] S. T. Hawk, "Disclosures of Maternal HIV Infection to Seronegative Children: A Literature Review," Journal of Social and Personal Relationships, Vol. 24, No. 5, 2007, pp. 657-673. doi:10.1177/0265407507081453

[11] D. A. Murphy, "HIV-Positive Mothers' Disclosure of Their Serostatus to Their Young Children: A Review," Clinical Child Psychology and Psychiatry, Vol. 13, No. 1, 2008, pp. 105-122. doi:10.1177/1359104507087464

[12] J. Rwemisisi, B. Wolff, A. Coutinho, H. Grosskurth and J. Whitworth, “'What If They Ask How I Got It?’ Dilemmas of Disclosing Parental HIV Status and Testing Children for HIV in Uganda," Health Policy and Planning, Vol. 23, No. 1, 2008, pp. 36-42. doi:10.1093/heapol/czm040

[13] E. W. Schrimshaw and K. Siegel, "HIV-Infected Mothers’ Disclosure to Their Uninfected Children: Rates, Reasons, and Reactions," Journal of Social and Personal Relationships, Vol. 19, No. 1, 2002, pp. 19-43. doi:10.1177/0265407502191002

[14] T. Tompkins, "Disclosure of Maternal HIV Status to Children: To Tell or Not To Tell ... That Is the Question,” Journal of Child and Family Studies, Vol. 16, No. 6, 2007, pp. 773-788. doi:10.1007/s10826-006-9124-Z

[15] L. Nam, K. Fielding, A. Avalos, T. Gaolathe, D. Dickinson, et al., "Discussing Matters of Sexual Health with Children: What Issues Relating to Disclosure of Parental HIV Status Reveal,” AIDS Care, Vol. 21, No. 3, 2009, pp. 389-395. doi:10.1080/09540120802270276

[16] A. Shaffer, D. J. Jones, B. A. Kotchick and R. Forehand, "Telling the Children: Disclosure of Maternal HIV Infection and Its Effects on Child Psychosocial Adjustment," Journal of Child and Family Studies, Vol. 10, No. 3, 2001, pp. 301-313. doi:10.1023/A:1012502527457

[17] D. Pilowsky, N. Sohler and E. Susser, "Reasons Given for Disclosure of Maternal HIV Status to Children," Journal of Urban Health, Vol. 77, No. 4, 2000, pp. 723734. doi:10.1007/BF02344033

[18] D. Kennedy, B. Cowgill, L. Bogart, R. Corona, G. Ryan, et al., "Parents' Disclosure of Their HIV Infection to Their Children in the Context of the Family," AIDS and Behavior, Vol. 14, No. 5, 2010, pp. 1095-1105. doi:10.1007/s10461-010-9715-y 
[19] L. Armistead, L. Tannenbaum, R. Forehand, E. Morse and P. Morse, "Disclosing HIV Status: Are Mothers Telling Their Children?” Journal of Pediatric Psychology, Vol. 26, No. 1, 2001, pp. 11-20. doi:10.1093/jpepsy/26.1.11

[20] R. O. Delaney, J. M. Serovich and J. Y. Lim, "Reasons for and against Maternal HIV Disclosure to Children and Perceived Child Reaction,” AIDS Care, Vol. 20, No. 7, 2008, pp. 876-880. doi:10.1080/09540120701767158

[21] A. H. Vallerand, E. Hough, L. Pittiglio and D. Marvicsin, "The Process of Disclosing HIV Serostatus between HIVPositive Mothers and their HIV-Negative Children," AIDS Patient Care and STDs, Vol. 19, No. 2, 2005, pp. 100-109. doi:10.1089/apc.2005.19.100

[22] M. B. Lee and M. J. Rotheram-Borus, "Parents' Disclosure of HIV to Their Children,” AIDS, Vol. 16, No. 16, 2002, pp. 2201-2207. doi:10.1097/00002030-200211080-00013

[23] T. Xu, Z. Yan, K. Rou, C. Wang, R. Ye, et al., "Disclosure of Parental HIV/AIDS to Children in Rural China,"
Vulnerable Children and Youth Studies, Vol. 2, No. 2, 2007, pp. 100-105. doi:10.1080/17450120701335791

[24] D. A. Murphy, M. E. Dello Stritto and W. N. Steers, "Maternal Disclosure of Mothers' HIV Serostatus to Their Young Children,” Journal of Family Psychology, Vol. 15, No. 3, 2001, pp. 441-450. doi:10.1037/0893-3200.15.3.441.

[25] E. Brackis-Cott, C. Mellins and M. Block, "Current Life Concerns of Early Adolescents and Their Mothers: Influence of Maternal HIV," The Journal of Early Adolescence, Vol. 23, No. 1, 2003, pp. 51-77. doi:10.1177/0272431602239130

[26] R. A. Ostrom, J. M. Serovich, J. Y. Lim and T. L. Mason, "The Role of Stigma in Reasons for HIV Disclosure and Non-Disclosure to Children,” AIDS Care, Vol. 18, No. 1, 2006, pp. 60-65. doi:10.1080/09540120500161769

[27] M. J. Rotheram-Borus, D. Flannery, E. Rice and P Lester, "Families Living with HIV," AIDS Care, Vol. 17, No. 8, 2005, pp. 978-987. doi:10.1080/09540120500101690. 